DOI: 10.19085/journal.sijbpg021002

\title{
How the operational level managers influence the corporate level strategies and their collective successful implementation
}

\author{
Alexander Braun \\ Heidelberg University, Bergheimer Str. 58, D-69115 Heidelberg, Germany.
}

OScholedge International Journal of Business Policy \& Governance (ISSN 2394-3351), Vol.02, Issue 10 (2015) p9-16. Published by: Scholedge R\&D Center [www.theSCHOLEDGE.org] [Email:sijbpg@scholedge.org]

\begin{abstract}
The planning is an integral part of the managers' task for the modern strategic business culture. The corporate strategies are formulated by the top level managers while the operational level managers are expected to follow those policy statements for their instructed implementation. But this is not the real and practical job of the operational level managers. Instead, they are the key role players in the effective development of the production and operations of the commercial entity. This paper reads the impact role of the operational managers on the corporate level policies. The paper establishes the fact that it the operational level managers who bring and affect the change by effectively implementing the top level plans and goals of the corporate level managers.
\end{abstract}

Keywords: Operational Management, Strategic management, Business Planning, Corporate effectiveness

\section{Study}

Operations administration is a multi-disciplinary field that spotlights on dealing with all parts of an association's operations. The common organization does different capacities as a piece of its operation. The separating of an organization's exercises into utilitarian classifications happens at an opportune time, even in an organization shaped and worked by a solitary person. Most organizations make a result or something to that affect or deliver an attractive administration. They should likewise complete a business and promoting capacity, a bookkeeping capacity, and an authoritative capacity to oversee representatives and the business all in all. Operations administration concentrates on the capacity of giving the item or administration. Their employment is to guarantee the creation of a quality decent and/or administration. They apply thoughts and advancements to build efficiency and decrease expenses, enhance adaptability to meet quickly changing client needs, guarantee a protected work environment for all representatives, and when conceivable help with guaranteeing astounding client administration.

Generally, the title "Operations Manager" is utilized as a part of organizations that create an unmistakable decent-makers all in all. In administration arranged organizations, the 
individual in charge of the operations chief part is frequently called by another name, one that addresses the administration being advertised. Illustrations incorporate undertaking chief, specialist, legal counselor, bookkeeper, office supervisor, datacenter director, and so forth.

Operation alludes to the coordination of those exercises in a business that are included in consolidating inputs with the end goal of delivering a yield that is esteemed by purchasers. This procedure is called worth including. For instance, a pack of oranges can experience certain techniques to transform it into containers of squeezed orange. The jugs of juice will be worth more than the first sack of oranges in light of the fact that, at every phase of generation, quality was included.

The operations office is in charge of gaining the inputs and conceiving the best generation techniques with the goal that esteem including happens in the most productive and successful way. Subsequently, the part of operations administration (and the operations supervisor) is to guarantee a smooth creation handle that adds to the yield of products and administrations of an association.

\section{Key issues in operations}

As an association creates arrangements and procedures to manage the open doors and difficulties that emerge in its specific working environment, it ought to plan a framework that is fit for delivering quality administrations and products in the amounts requested and in the time spans important to meet the organizations commitments.

\section{Outlining the System}

Outlining the framework starts with item advancement. Item advancement includes deciding the qualities and components of the item or administration to be sold. It ought to start with an evaluation of client needs and in the long run develop into a nitty gritty item plan. The offices and gear utilized as a part of creation, and in addition the data frameworks expected to screen and control execution, are each of the a piece of this framework configuration process. Truth be told, assembling procedure choices are fundamental to a definitive achievement or disappointment of the framework. Of all the auxiliary choices that the operations supervisor makes, the one liable to have the best effect on the operation's prosperity is decision of the procedure innovation. This choice answers the essential inquiry: How will the item be made?

Item plan is a basic undertaking in light of the fact that it decides the qualities and elements of the item, and additionally how the item capacities. Item outline decides an item's expense and quality, and additionally its elements and execution. These are essential elements on 
which clients settle on acquiring choices. As of late, new plan models, for example, Design for Manufacturing and Assembly (DFMA) have been executed to enhance item quality and lower expenses. DFMA concentrates on working issues amid item outline. This can be basic despite the fact that plan expenses are a little piece of the aggregate expense of an item, on the grounds that, systems that waste crude materials or copy exertion can have a significant negative effect on a business' working gainfulness. Another development like DFMA in its accentuation on configuration is Quality Functional Deployment (QFD). QFD is an arrangement of arranging and correspondence schedules that are utilized to enhance item outline by centering configuration endeavors on client needs.

Procedure outline depicts how the item will be made. The procedure plan choice has two noteworthy segments: a specialized (or building) segment and a scale economy (or business) segment. The specialized segment incorporates selecting hardware and selecting a grouping for different periods of operational generation.

The scale economy or business segment includes applying the correct measure of motorization (instruments and hardware) to make the association's work constrain more gainful. This incorporates deciding: 1) If the interest for an item is sufficiently extensive to legitimize large scale manufacturing; 2) If there is adequate assortment in client request so that adaptable generation frameworks are required; and 3) If interest for an item is so little or occasional that it can't bolster a committed creation office.

Office configuration includes deciding the limit, area, and format for the creation office. Limit is a measure of an organization's capacity to give the requested item in the amount asked for by the client in a convenient way. Scope organization includes evaluating interest, deciding the limit of offices, and choosing how to change the association's ability to react to request.

Office area is the arrangement of an office as for its clients and suppliers. Office area is a vital choice in light of the fact that it is a long haul responsibility of assets that can't undoubtedly or economically be changed. While assessing an area, administration ought to consider client accommodation, introductory speculation important to secure area and offices, government motivating forces, and working transportation costs. What's more, subjective variables, for example, personal satisfaction for representatives, transportation foundation, and work environment ought to additionally be taken under thought.

Office format is the game plan of the workspace inside of an office. It considers which divisions or work ranges ought to be neighboring each other so that the stream of item, data, and individuals can move rapidly and productively through the creation framework. 
After all things considered considering the items and administrations requested by clients, qualities and shortcomings of contenders, nature, and the company's own qualities, shortcomings, societies, and assets, capable firms can detail their vision as communicated through the statement of purpose. This announcement communicates the association's qualities and desires; fundamentally its reason or reason for presence. In view of this statement of purpose the firm will figure its business technique. This business technique is a long haul arrangement for finishing the mission put forward in the statement of purpose. Every capacity inside of the business can then determine its own procedure in backing of the company's general business technique (money related system, showcasing methodology, and operations technique).

Operations procedure is the aggregate solid activities picked, commanded, or animated by corporate technique. It is, obviously, actualized inside of the operations capacity. This operations methodology ties the different operations choices and activities into a strong predictable reaction to focused strengths by connecting firm approaches, projects, frameworks, and activities into a methodical reaction to the aggressive needs picked and imparted by the corporate or business procedure. In more straightforward terms, the operations procedure indicates how the firm will utilize its operations capacities to bolster the business methodology.

Operations methodology has a long haul sympathy toward how to best decide and add to the association's real operations assets so that there is a high level of similarity between these assets and the business system. Exceptionally wide inquiries are tended to with respect to how real assets ought to be arranged keeping in mind the end goal to accomplish the company's corporate targets. A percentage of the issues of significance incorporate long haul choices with respect to limit, area, procedures, innovation, and timing.

The accomplishment of world-class status through operations requires that operations incorporated with alternate capacities at the corporate level. In wide terms, an operation has two critical parts it can play in reinforcing the company's general methodology. One alternative is to give forms that give the firm a particular favorable position in the commercial center. Operations will give a showcasing edge through unmistakable, one of a kind innovation advancements in procedures that contenders can't coordinate.

The second part that operations can play is to give facilitated backing to the key routes in which the association's items win orders over their rivals, otherwise called unmistakable skills. The company's operations methodology must be helpful for building up an arrangement of approaches in both procedure decision and base outline (controls, strategies, frameworks, and so on.) that are reliable with the association's particular competency. Most firms offer access to the same procedures and innovation, so they 
typically vary little in these ranges. What is diverse is the extent to which operations coordinates its procedures and framework to its particular skills.

\section{Execution}

Once an item is created and the assembling framework is composed, it must be actualized, an errand regularly more effectively examined than completed. On the off chance that the framework configuration capacity was done completely, it will have rendered a usage arrangement which will direct exercises amid execution. Regardless, there will unavoidably be changes required. Choices will must be made all through this usage period about tradeoffs. For instance, the expense of the initially arranged transport line may have risen. This change will make it important to consider changing the predetermined transport line for another model. This, obviously, will affect upon different frameworks connected to the transport line and the full ramifications of every one of these progressions will must be evaluated and contrasted with the expense of the cost increment on the first transport line.

\section{Arranging and Forecasting}

Running an effective generation framework requires a lot of arranging. Long-extend choices could incorporate the quantity of offices required to address client issues or concentrate how innovative change may influence the routines used to create administrations and merchandise. The time skyline for long haul arranging shifts with the business and is subject to both multifaceted nature and size of proposed changes. Regularly, in any case, long haul arranging may include deciding work power size, creating preparing projects, working with suppliers to enhance item quality and enhance conveyance frameworks, and deciding the measure of material to arrange on a total premise. Transient booking, then again, is worried with creation making arrangements for particular employment orders (who will take every necessary step, what hardware will be utilized, which materials will be expended, when the work will start and end, and what method of transportation will be utilized to convey the item when the request is finished).

\section{Dealing with the System}

Dealing with the framework includes working with individuals to energize interest and enhance hierarchical execution. Participative administration and cooperation are a key a portion of fruitful operations, as are authority, preparing, and culture. What's more, material administration and quality are two key ranges of concern.

Material administration incorporates choices with respect to the acquisition, control, taking care of, capacity, and appropriation of materials. Material administration is turning out to be more vital on the grounds that, in numerous associations, the expenses of obtained 
materials involve more than 50 percent of the aggregate generation cost. Inquiries with respect to amounts and timing of material requests should be tended to here also when organizations measure the characteristics of different suppliers.

While operations administration is centered around the generation of merchandise and/or administrations in an association, its significance to the general association can't be disparaged. At the point when an association's operations are legitimately dealt with, the elements of every single other office are smooth, and when an association's operations are overseen dishonorably, all different offices endure.

A HR division can make great expectations on the requirement for staff, to grow great job depictions, and to enroll and prepare all the more effortlessly when operations are run well. Employments are less demanding to fill, and turnover stays lower. In the event that an operations are not run well, the results for HR are bad. For instance, the HR individuals can't grow great job depictions and necessities for the creation division, think that its more hard to enroll and prepare, and confront higher turnover, which is expensive to any association.

A bookkeeping division that is supporting a smooth operation can pay materials and supplies charges expeditiously since a well-run operation arranges ahead. Finance is anything but difficult to handle, with unsurprising expenses. Be that as it may, if the operation is run inadequately, unsurprising expenses, for example, these are hard to discover, making it troublesome for the bookkeeping office to carry out its employment well.

An account office, which is accused of discovering capital, either through obligation or value financing, can raise cash much all the more effectively with a smooth-running, fruitful operations division, having the capacity to indicate high efficiency, trimming of expenses, and great booking to take care of demand. Then again, if the account division can just demonstrate a record of inefficiencies, a lot of or too little stock, and uneven profitability, it is hard to raise capital.

The showcasing division's prosperity is dependent on fruitful operations also. It must have a fruitful and on-time item or administration to showcase. It must have an item or administration that works and that is being created in suitable numbers. In the event that it doesn't, if there is a disgraceful item or an item for which generation is behind, the best advertising on the planet is of little utilize.

The lawful division's capacity to bolster operations is reliant upon an all around oversaw operation, as well. A well-made item does not prompt risk claims. Whenever supplies and materials are made arrangements for, there is less probability of agreement debate with 
suppliers. At the point when items are delivered on-time, there is less probability of agreement debate with buyer.

All things considered, operations are the heart of any association that is giving a decent and/or an administration. At the point when operations are overseen well, it makes the capacity of every single other office less demanding, and then again, when operation are overseen inadequately, all different offices endure.

\section{Conclusion}

Subsequently, Operations administration includes "administering, outlining, controlling the procedure of creation and updating business operations in the generation of merchandise and/or administrations." Operations administration capacities contrast contingent on the reason for the association. In an assembling setting, for example, a manufacturing plant, operations administration would incorporate outlining proficient procedures to deliver the item, convenient procurement of crude materials, guaranteeing satisfactory quantities of appropriately prepared laborers, and legitimate upkeep of gear. Operations administration in an administration setting would concentrate on protecting that laborers are sufficiently prepared, that client administration areas are prepared as required and are alright for workers and general society, that administrations are reconsidered as directed by client information or aggressive strengths.

\section{References}

Åhlström, P., \& Westbrook, R. (1999). Implications of mass customization for operations management: an exploratory survey. International Journal of Operations \& Production Management, 19(3), 262-275.

Applegate, L. M., Austin, R. D., \& McFarlan, F. W. (2003). Corporate information strategy and management: text and cases. New York, NY: McGraw-Hill Irwin.

Bartlett, C. A., Ghoshal, S., Bartlett, C., \& Doz, Y. (1990). Managing innovation in the transnational corporation. Managing the global firm, 215-255.

Benson, P. G., Saraph, J. V., \& Schroeder, R. G. (1991). The effects of organizational context on quality management: an empirical investigation. Management science, 37(9), 1107-1124.

Burgelman, R. A. (1983). A process model of internal corporate venturing in the diversified major firm. Administrative Science Quarterly, 223-244.

Evans, J. R., \& Lindsay, W. M. (1999). The management and control of quality. 
Kerzner, H. R. (2013). Project management: a systems approach to planning, scheduling, and controlling. John Wiley \& Sons.

Kleindorfer, P. R., Singhal, K., \& Wassenhove, L. N. (2005). Sustainable operations management. Production and operations management, 14(4), 482-492.

Meredith, J. R., Raturi, A., Amoako-Gyampah, K., \& Kaplan, B. (1989). Alternative research paradigms in operations. Journal of operations management, 8(4), 297-326.

Russell, R. S., \& Taylor-lii, B. W. (2008). Operations management along the supply chain. John Wiley \& Sons.

Salvendy, G. (Ed.). (2001). Handbook of industrial engineering: technology and operations management. John Wiley \& Sons.

Slack, N. (1994). The importance-performance matrix as a determinant of improvement priority. International Journal of Operations \& Production Management, 14(5), 59-75.

Upton, D. M. (1995). Flexibility as process mobility: the management of plant capabilities for quick response manufacturing. Journal of Operations Management, 12(3), 205-224.

Ward, P. T., McCreery, J. K., Ritzman, L. P., \& Sharma, D. (1998). Competitive priorities in operations management. Decision Sciences, 29, 1035-1046. 